\title{
Stability of a cyanidin-3-O-glucoside extract obtained from Arbutus unedo L. and incorporation into wafers for colouring purposes
}

\author{
Cecilia Jiménez López ${ }^{\mathrm{a}}$, Cristina Caleja ${ }^{\mathrm{a}, \mathrm{b}}$, M.A. Prieto ${ }^{\mathrm{a}, \mathrm{c}}$, Marina Sokovic ${ }^{\mathrm{d}}$, Ricardo C. Calhelha ${ }^{\mathrm{a}}$, \\ Lillian Barros $^{\mathrm{a}, *}$, Isabel C.F.R. Ferreira ${ }^{\mathrm{a}, *}$ \\ a Centro de Investigação de Montanha (CIMO), Instituto Politécnico de Bragança, Campus de Santa Apolónia, 5300-253 Bragança, Portugal \\ ${ }^{\mathrm{b}}$ Laboratoire of Separation and Reaction Engineering (LSRE), Associate Laboratory LSRE/LCM, IPB, Campus de Santa Apolónia, 1134, 5301-857 Bragança, Portugal \\ ${ }^{\mathrm{c}}$ Nutrition and Bromatology Group, Faculty of Food Science and Technology, University of Vigo, Ourense Campus, E32004 Ourense, Spain \\ d University of Belgrade, Department of Plant Physiology, Institute for Biological Research "Siniša Stanković", Bulevar Despota Stefana 142, 11000 Belgrade, Serbia
}

\section{A R T I C L E I N F O}

\section{Keywords:}

Arbutus unedo L.

Anthocyanins

Cyanidin-3-O-glucoside

Stability

Wafers

\begin{abstract}
A B S T R A C T
An extract from Arbutus unedo fruits, rich in anthocyanins, was studied as a natural colorant with bioactive properties (antioxidant, antimicrobial and cytotoxic). The aqueous stability of the extract was monitored using the anthocyanins' content as response (determined by HPLC-DAD) in function of time, temperature and $\mathrm{pH}$. Aided by mechanistic/phenomenological models, the conditions that favours the stabilization of the extract were provided, highlighting the suitability of the colorant for pastry/bakery products. As a case study, the extract was incorporated into wafers and the changes on the nutritional profile, free sugars, fatty acids and antioxidant properties were monitored during 6 days of storage. The results provide information for: i) potential application of the rich extract in anthocyanins for producing a natural colorant with bioactive properties; and ii) shelf-life predictions. The extract incorporation did not cause changes in the nutritional components of wafers but added colorant and antioxidant properties.
\end{abstract}

\section{Introduction}

Anthocyanins are secondary metabolites of plants belonging to the group of phenolic compounds, colouring from fruits and flowers, to roots and seeds (Cavalcanti, Santos, \& Meireles, 2011). Besides that, their beneficial effects to human health are well known: thanks to the presence of phenolic hydroxyl groups, they show antioxidant properties, preventing pathologies such as cardiovascular diseases, cancer and diabetes (Ge \& Ma, 2013; Prior \& Wu, 2006). Several studies also attribute to these compounds chemopreventive and chemotherapeutic capacity, due to their ability to inhibit tumour cells' growth (Ding et al., 2006). However, their stability also deserves a special mention due to a chemical structure very susceptible to degradation by several factors, as temperature, $\mathrm{pH}$, presence of oxygen and even light (Cevallos-Casals \& Cisneros-Zevallos, 2004; Garzón, 2008).

Although artificial colours began to dominate the market for paints and textiles, in the nineteenth century these pigments started to be highly used in food industry to improve the appearance of certain foods. Initially, these colorants began to be applied in wine, pasta and butter (Ibañez, Torre, \& Irigoyen, 2003), but their use was not fully regulated. The use of artificial colorants by the industry raised the concern of consumers, due to some reports on health problems (hyperactivity and allergic reactions) (Esatbeyoglu, Wagner, Schini-Kerth, \& Rimbach, 2015). Nowadays, it is a subject very well regulated, both at continental and world level, through various committees created by WHO, FAO and European Communities' Commission (EFSA). The extensive use of artificial colorants to make food more attractive for consumers (Ibañez et al., 2003) has been related to harmful effects, which increased the interest for labels as "natural" or "without artificial additives" (Carocho, Barreiro, Morales, \& Ferreira, 2014; Martins, Roriz, Morales, Barros, \& Ferreira, 2016).

Following the legal and commercial requirements that are emerging, there is a trend of the food industry for natural ingredients (Esatbeyoglu et al., 2015). In the case of colorants, anthocyanins represent an attractive and natural alternative to the artificial ones. Anthocyanins stability is essential to ensure the quality and delivery of these bioactive components. However, natural extracts rich in anthocyanins are susceptible to degradation by several factors and the stability of these compounds during its application is a crucial step. The main identified factors affecting the stability are time $(t)$, temperature (T) and pH (Komatsu et al., 2014; Zhu et al., 2002). Nonetheless, other factors such as light exposure, moisture content, metal ions content,

\footnotetext{
* Corresponding authors.

E-mail addresses: lillian@ipb.pt (L. Barros), iferreira@ipb.pt (I.C.F.R. Ferreira).
} 
etc., have also been pointed out as relatively important (Li, Taylor, \& Mauer, 2011).

Arbutus unedo L. is a shrub belonging to the subfamily Vaccionioideae (or Arbutoideae, according to the different authors) of the Ericaceae family (Miguel, Faleiro, Guerreiro, \& Antunes, 2014). The edible fruits are grown in this shrub and are popularly recognized for their beneficial properties, particularly in the treatment of some symptomatology's (Ziyyat et al., 2002). The antimicrobial and antioxidant properties of the fruits are described in the literature and are associated, according to some authors, with the presence of phenolic compounds (Guimarães et al., 2013; Miguel et al., 2014).

Therefore, the aims of this study were to evaluate: 1 ) the bioactive properties (antioxidant, antimicrobial and cytotoxic) of the colorant extract produced; and 2) the stability of the extract considering the main affecting variables of $t, T$ and $p H$ in aqueous solution, by analysing the anthocyanins content by HPLC-DAD. Once the extract was stabilized, it was incorporated into wafers as a case study of the potential application in pastry products. Nutritional profile, free sugars, fatty acids and antioxidant activity were monitored after the wafers were baked, and after 3 and 6 days of storage.

\section{Material and methods}

\subsection{Preparation of an anthocyanins rich extract from $A$. unedo fruits}

\subsubsection{Source material}

The fruits of $A$. unedo L. (strawberry tree) were provided by a local producer of Torre de Moncorvo, Portugal. The fruits $(1 \mathrm{~kg})$ were lyophilized (FreeZone 4.5, Labconco, Kansas City, MO, USA) and reduced to powder $(\sim 20$ mesh). The obtained powder was then mixed to guarantee the homogeneity of the samples, which were stored in a freezer (average $-20^{\circ} \mathrm{C}$ ), and protected from light, until further analysis.

\subsubsection{Heat assisted extraction}

The extract rich in cyanidin-3-O-glucoside was obtained from $A$. unedo $\mathrm{L}$. following the optimized process previously reported by Jiménez et al. (2018). Briefly, the samples $(600 \mathrm{mg})$ were placed in a beaker with $80 \%$ of acidified ethanol (acidified with $0.05 \%$ of hydrochloric acid) in order to obtain the desired solid/liquid ratio $(10 \mathrm{~g} / \mathrm{L})$. The beaker was placed in a thermostatic water bath under continuous electro-magnetic stirring using a CIMAREC i Magnetic Stirrer (Thermo Scientific, San Jose, CA, USA) with a fixed agitation speed (500 rpm) for $5 \mathrm{~min}$ at $90^{\circ} \mathrm{C}$. Then, the extract solution was filtered through Whatman $\mathrm{n}^{\circ} 4$ paper and evaporated at $35^{\circ} \mathrm{C}$ to remove the ethanol, frozen and lyophilized, to obtain a dry extract. As reported by Jiménez et al. (2018), following this procedure, it was obtained a residual extract of $\sim 60 \%$ of the total fruit $\mathrm{dw}$, with a total anthocyanins content of $\sim 500 \mu \mathrm{g} / \mathrm{g}$ of fruit $\mathrm{dw}(\sim 800 \mu \mathrm{g} / \mathrm{g}$ of extracted material $)$.

\subsection{Evaluation of the bioactive properties of the anthocyanins rich extract}

A brief summary of the work performed is presented in Fig. 1. Next, each step performed will be described in detail.

\subsubsection{General}

The extract rich in anthocyanins ( $125 \mathrm{~g}$ ) was dissolved in acidified distilled water $(500 \mathrm{~mL}, 0.05 \% \mathrm{HCl})$. Dry extracts were further diluted to different concentrations to be submitted to the in vitro bioassays: i) final concentration $20 \mathrm{mg} / \mathrm{mL}$ in $80 \%$ of ethanol $(0.05 \% \mathrm{HCl})$ and further diluted to working solutions of $5-0.156 \mathrm{mg} / \mathrm{mL}$, for antioxidant activity; ii) stock concentration of $8 \mathrm{mg} / \mathrm{mL}$, re-dissolved in water $(0.05 \% \mathrm{HCl})$ and further diluted to $400-1.5 \mu \mathrm{g} / \mathrm{mL}$ working solutions for cytotoxic evaluation; and iii) the extracts were diluted in appropriate media according to bacteria requirements and the $\mathrm{pH}$ was adjusted with $0.05 \% \mathrm{HCl}$ and successive dilutions were carried out in the wells (1-0.1 mg/mL of final concentration).

2.2.1.1. Evaluation of antioxidant properties. DPPH radical-scavenging activity and reducing power were evaluated using ELX800 microplate Reader (Bio-Tek Instruments, Inc., Winooski, VT, USA) at 515 and $690 \mathrm{~nm}$, respectively. $\beta$-Carotene bleaching inhibition and lipid peroxidation inhibition, using the thiobarbituric acid reactive substances - TBARS, were evaluated spectrophotometrically at 470 and $532 \mathrm{~nm}$, respectively. The complete protocols were previously described by the authors (Sarmento, Barros, Fernandes, Carvalho, and Ferreira, 2015).

2.2.1.2. Evaluation of cytotoxicity properties. The extract was redissolved in water at a concentration of $8 \mathrm{mg} / \mathrm{mL}$. According with Guimarães et al. (2013), four human tumour cell lines were used: MCF7 (breast adenocarcinoma), NCI-H460 (non-small cell lung cancer), HeLa (cervical carcinoma) and HepG2 (hepatocellular carcinoma). The cell growth inhibition was measured using sulforhodamine B assay, where the amount of pigmented cells is directly proportional to the total protein mass and, therefore, to the number of bounded cells.

For hepatotoxicity evaluation, a cell culture was prepared from a freshly harvested porcine liver which was acquired from certified slaughterhouses and was used in order to obtain the cell culture, designated as PLP2. A phase-contrast microscope was used to monitor the growth of the cell cultures. They were sub-cultured and plated in 96 well plates (density of $1.0 \times 10^{4}$ cells/well). Dulbecco's modified eagle's medium (DMEM) was used, with $10 \%$ of Fetal bovine serum (FBS), $100 \mathrm{U} / \mathrm{mL}$ of penicillin and $100 \mu \mathrm{g} / \mathrm{mL}$ of streptomycin. The growth inhibition was evaluated using the sulphorhodamine B (SRB) assay, as previously described (Guimarães et al., 2013).

2.2.1.3. Evaluation of antimicrobial properties. Following the procedure previously described by Soković, Glamočlija, Marin, Brkić, and van Griensven (2010), the antibacterial activity was evaluated against four Gram-negative bacteria: Escherichia coli (ATCC 35210), Pseudomonas aeruginosa (ATCC 27853), Salmonella typhimurium (ATCC 13311), Salmonella enteritidis (ATCC 13076), and four Gram-positive bacteria: Staphylococcus aureus (ATCC 6538), Bacillus cereus (clinical isolate), Micrococcus flavus (ATCC 10240), and Listeria monocytogenes (NCTC 7973).

Following the procedure previously described by Soković \& van Griensven (2006), the antifungal activity was evaluated against eight fungi: Aspergillus fumigatus (ATCC 1022), Aspergillus ochraceus (ATCC 12066), Aspergillus versicolor (ATCC 11730), Penicillium funiculosum (ATCC 36839), Penicillium ochrochloron (ATCC 9112), Candida crusei (clinical isolate) and Penicillium verrucosum (food isolate).

\subsubsection{Response evaluation and statistical analysis}

Antioxidant responses were evaluated by the $E C_{50}$ values (sample concentration providing $50 \%$ of antioxidant activity or 0.5 of absorbance in the reducing power assay) and expressed in $\mu \mathrm{g} / \mathrm{mL}$. Trolox was used as positive control in all the assays.

Cytotoxicity responses were determined by the $G_{50}$ values (sample concentration providing $50 \%$ of cytotoxic activity) and the results were expressed in $\mu \mathrm{g} / \mathrm{mL}$. Ellipticine was used as a positive control.

Antimicrobial responses were evaluated by the minimum inhibitory (MIC) and minimum bactericidal or fungicidal (MBC or $M F C$ ) concentrations and results were expressed in $\mu \mathrm{g} / \mathrm{mL}$. Streptomycin and ampicillin were used as positive controls for bacteria growth, while bifonazole and ketokonazole were used as controls for fungi growth.

In all cases the assays were carried out in triplicate. The results were expressed as mean values and standard deviation (SD). 


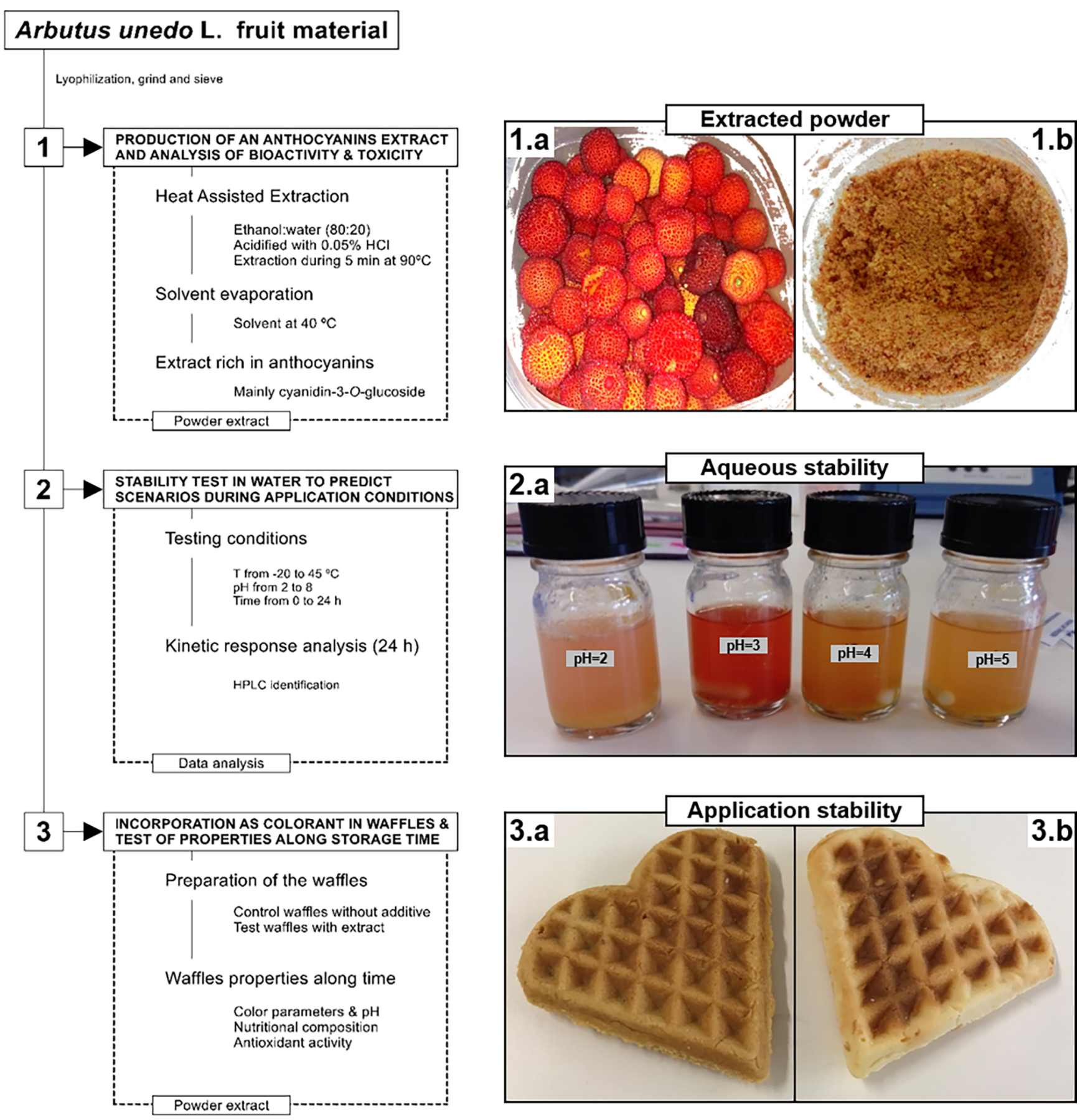

Fig. 1. Summarized diagram describing work performed: Section 1 shows the extraction process of anthocyanin compounds, Fig. 1.a and $\mathrm{b}$ presents the $A$. unedo fruit and extract, respectively; Section 2 shows the stability in aqueous solution systems considering its potential application in food matrices (Fig. 2.a shows the differences caused by the $\mathrm{pH}$ variable); and Section 3 shows the visual results of $A$. unedo extract rich in cyanidin-3-O-glucoside incorporated into wafers (Fig. 3.a shows wafer with A. unedo extract and 3.b control wafer).

\subsection{Stability of the of the anthocyanins rich extract in aqueous solution systems}

A brief summary of the work performed is presented in Fig. 1. Next, each step performed will be described in detail.

\subsubsection{General procedure}

The extract rich in anthocyanins ( $125 \mathrm{~g}$ ) was dissolved in acidified distilled water $(500 \mathrm{~mL}, 0.05 \% \mathrm{HCl})$. This solution was divided in 5 different flasks with $100 \mathrm{~mL}$ and adjusted with the addition of $\mathrm{HCl}(1 \mathrm{M})$ or $\mathrm{NaOH}(3 \%)$ to different $p H$ values $(2,3.5,5,6.5$ and 8$)$. Then, the samples were subdivided in amber vials containing $2 \mathrm{~mL}$ (50 vials per $\mathrm{pH}$ tested) and the samples were stored at different temperatures of 4 , $25,40,55$ and $70^{\circ} \mathrm{C}$ for monitoring of the anthocyanin stability along the time $(t)$. Samples were collected at different $t$ values of the storage period depending on the $T$ applied, for example at all $\mathrm{pH}$ values, at $4{ }^{\circ} \mathrm{C}$ only $3 t$ values were used $(0,72$ and $140 \mathrm{~h})$, meanwhile at $70{ }^{\circ} \mathrm{C} 12 t$ values were used $(0,2,4,8,12,20,48,72,96,140,164,190 \mathrm{~h})$. A total of 250 individual experimental points were collected to understand the patterns behind the stability of the extract in aqueous solution. As response criteria, the anthocyanins content was determined through HPLC-DAD, at each period of time. All independent measures were 
obtained in triplicate $(\mathrm{n}=3)$.

\subsubsection{Identification and quantification of anthocyanins by HPLC-DAD}

Each individual experimental point was filtered through a $0.22 \mu \mathrm{m}$ disposable LC filter disk before chromatographic analysis, which was performed with a HPLC-DAD-ESI/MSn (Dionex Ultimate 3000 UPLC, Thermo Scientific, San Jose, CA, USA) system. The separation was achieved on a Waters Spherisorb S3 ODS-2 C18 $(3 \mu \mathrm{m}$, $4.6 \mathrm{~mm} \times 150 \mathrm{~mm}$, Waters, Milford, MA, USA) operating at $35^{\circ} \mathrm{C}$. The solvents used were: (A) $0.1 \%$ TFA in water, and (B) $100 \%$ acetonitrile. The gradient elution followed these parameters: $10 \% \mathrm{~B}$ for $3 \mathrm{~min}$, from 10 to $15 \%$ B for $12 \mathrm{~min}, 15 \%$ B for $5 \mathrm{~min}$, from 15 to $18 \%$ B for $5 \mathrm{~min}$, from 18 to $30 \%$ B for $20 \mathrm{~min}$, from 30 to $35 \%$ B for $5 \mathrm{~min}$, and from 35 to $10 \% \mathrm{~B}$ for $10 \mathrm{~min}$. The resulting total run time was $60 \mathrm{~min}$, followed by column reconditioning of $10 \mathrm{~min}$, using a flow rate of $0.5 \mathrm{~mL} / \mathrm{min}$. Detection was carried out by DAD, using $520 \mathrm{~nm}$ as the preferred wavelength. Data acquisition was carried out with Xcalibur ${ }^{\circledR}$ data system (Thermo Finnigan, San Jose, CA, USA). A total of three anthocyanin compounds (Fig. A1, Supplementary material) were found and identified: delphinidin-3-O-glucoside (C1), cyanidin-3-O-glucoside (C2) and cyanidin-3-O-pentoside (C3), as previously described by Jiménez et al. (2018). For quantitative analysis, a 5-level calibration curve was obtained by injection of known concentrations $(50-0.25 \mu \mathrm{g} / \mathrm{mL})$ of cyanidin-3-O-glucoside $\left(y=243287 x-1000000 ; R^{2}=0.9953\right)$.

\subsubsection{Responses evaluation and statistical analysis}

The anthocyanins content was studied as function of mechanistic and phenomenological equations typically applied in similar processes.

2.3.3.1. Individual model for the analysis of the stability variable effects. Effect of the time on the stability response

For the $t$ effect, a typical exponential function was applied:

$e(t)=k \exp (-r t)$

where $k$ represents the starting point and $r$ is the decay degradation rate of the reaction.

\section{Effect of the temperature on the stability response}

The Arrhenius equation establishes that the rate constant of a chemical reaction is a function of the absolute $T$ according to the following relation:

$e(T)=A \exp \left(-\frac{E a}{R T}\right)$

where the pre-exponential factor $A$ represents the frequency of collisions among reacting molecules, $E a$ is the activation energy $(\mathrm{kJ})$ and $R$ the constant of gases $(8.31 \mathrm{~kJ} / \mathrm{mol}$.K). In context, $A$ and $E a$ can be considered as fitting parameters.

Effect of the $p H$ on the stability response

The characteristic solution for the description of the $p H$ effect is the exponential function, similar to the one used for $t$ effect, that is usually found in many biological system responses (Komatsu et al., 2014; Prieto, Vázquez, \& Murado, 2012b) and can be expressed as follows:

$e(p H)=s \exp (-b p H)$

where $s$ represents the starting point and $b$ is the degradation rate of the reaction.

2.3.3.2. Multivariable analysis. To be able to develop a multivariable analysis of these three variables, the logical approach is to insert the equations that take control of $\mathrm{pH}$ and $T$ into Eq. (1) that governs the time variable by modifying its parameters, the starting value $(k)$ and the degradation rate $(r)$. Even if the three variables are fully independent, any event that may occur in the surrounding environment of a reaction must be always referred to the time variable. Therefore, a global possible description of the stability at the molecular level could be described by the following approach: $e(t, p H, T)=k \cdot \exp (-r t) \quad$ where $\quad \begin{aligned} & k(p H, T)=k \times e(T) \times e(p H) \\ & r(p H, T)=r \times e(T) \times e(p H)\end{aligned}$

where $k$ represents the starting point and $r$ is the degradation rate of the reaction caused by the effect of time as described Eq. (1) but modified by the governing equations of the effect of $T$ (Eq. (2)) and $p H$ (Eq. (3)).

2.3.3.3. Numerical methods and statistical analysis. Fitting procedures, coefficient estimates and statistical calculations were performed as previously described (Pinela et al., 2016). In brief, a) the coefficient measurement was performed using the nonlinear least-square (quasiNewton) method provided by the macro "Solver" in Microsoft Excel, which allows minimizing the sum of the quadratic differences between the observed and model-predicted values; $b$ ) the coefficient significance was evaluated using the 'SolverAid' to determine the parametric confidence intervals. Not statistically significant terms (pvalue $>0.05$ ) were dropped to simplify the model; and c) the model reliability was verified using the following criteria: i) the Fisher $F$-test ( $\alpha=0.05$ ) was used to determine whether the constructed models were adequate to describe the observed data; ii) the 'SolverStat' macro was used for the assessment of parameter and model prediction uncertainties; iii) the $\mathrm{R}^{2}$ was interpreted as the proportion of variability of the dependent variable explained by the model.

\subsection{Incorporation of the anthocyanins rich extract in wafers as natural colorant additives. Evaluation of colour, nutritional composition and antioxidant activity along storage time}

A brief summary of the work performed is presented in Fig. 1. Next, each step performed will be described in detail.

\subsubsection{Preparation of the wafers samples}

A traditional formulation was followed to prepare the wafers: $165 \mathrm{~g}$ of wheat flour was thoroughly mixed with $100 \mathrm{~g}$ of sugar and $1 \mathrm{~g}$ of baking powder. Then, $130 \mathrm{~g}$ of butter were sequentially added to the mixture while mixing vigorously with a hand mixer at $450 \mathrm{~W}$ during $5 \mathrm{~min}$ and after 2 eggs and $20 \mathrm{~mL}$ of lemon juice were added. Two lots of wafers (18 per lot, 6 wafers for each storage time) were prepared: i) control wafers - without the addition of any substance; and ii) wafers with the $A$. unedo extract rich in cyanidin-3-O-glucoside $(5.50 \mathrm{~g})$. The wafers were baked in a wafers machine for $10 \mathrm{~min}$. All samples were lyophilized, finely crushed and analysed, in triplicate, immediately after preparation and after three and six days of storage (at room temperature and packed in a sealed plastic bags covered with aluminium paper).

\subsubsection{Evaluation of colour parameters and $\mathrm{pH}$ of the wafers along storage} time

The colour of the samples was measured using a colorimeter (model CR-400, Konica Minolta Sensing Inc., Tokyo, Japan). The illuminate C was used and a diaphragm aperture of $8 \mathrm{~mm}$ and previously calibrated against a standard white tile. The CIE $L^{*}$ (lightness), $a^{*}$ (greenness/ redness), $b^{*}$ (blueness/yellowness) colour space values were registered using a data software "Spectra Magic Nx" (version CM-S100W 2.03.0006) (Caleja et al., 2016). The samples' pH was measured by inserting the pH-meter (HI 99161, Hanna Instruments, Woonsocket, Rhode Island, USA) in the waffle sample. The determinations were performed in triplicate for each sample.

2.4.3. Evaluation of the proximate composition, free sugars, fatty acids and antioxidant activity of the wafers along storage time

- The contents of protein, fat, carbohydrates and ash, were determined following the AOAC methods (AOAC International, 2016). Total energy was calculated following the equation: Energy 
Table 1

Antioxidant, cytotoxic and antimicrobial activities of Arbutus unedo L. extract $($ mean $\pm S D)$.

\begin{tabular}{|c|c|c|c|c|}
\hline \multicolumn{3}{|l|}{ Antioxidant activity } & $\begin{array}{l}\text { A. unedo } \\
\text { extract } \\
E C_{50} \\
(\mu \mathrm{g} / \mathrm{mL})\end{array}$ & $\begin{array}{l}\text { Control } \\
\text { (Trolox) } \\
E C_{50} \\
(\mu \mathrm{g} / \mathrm{mL})\end{array}$ \\
\hline \multicolumn{3}{|c|}{ DPPH scavenging activity } & $295 \pm 13$ & $41 \pm 1$ \\
\hline \multicolumn{3}{|c|}{ Reducing power } & $447 \pm 4$ & $41.7 \pm 0.3$ \\
\hline \multicolumn{3}{|c|}{$\beta$-carotene bleaching inhibition } & $901 \pm 41$ & $18 \pm 1$ \\
\hline \multicolumn{3}{|c|}{ Thiobarbituric acid reactive substances (TBARS) } & $257 \pm 4$ & $23 \pm 1$ \\
\hline \multirow{2}{*}{\multicolumn{3}{|c|}{ Cytotoxicity in tumour cell lines }} & $\begin{array}{l}\text { A. unedo } \\
\text { extract }\end{array}$ & $\begin{array}{l}\text { Control } \\
\text { (Ellipticine) }\end{array}$ \\
\hline & & & $\begin{array}{l}G I_{50} \\
(\mu \mathrm{g} / \mathrm{mL})\end{array}$ & $\begin{array}{l}G I_{50} \\
(\mu \mathrm{g} / \mathrm{mL})\end{array}$ \\
\hline \multirow{4}{*}{\multicolumn{3}{|c|}{$\begin{array}{l}\text { NCI-H460 (non-small cell lung carcinoma) } \\
\text { HeLa (cervical carcinoma) } \\
\text { HepG2 (hepatocellular carcinoma) } \\
\text { MCF-7 (breast carcinoma) }\end{array}$}} & $>400$ & $1.0 \pm 0.1$ \\
\hline & & & $350 \pm 10$ & $1.91 \pm 0.06$ \\
\hline & & & $>400$ & $1.1 \pm 0.2$ \\
\hline & & & $338 \pm 14$ & $0.91 \pm 0.04$ \\
\hline \multirow{2}{*}{\multicolumn{3}{|c|}{ Cytotoxicity in non-tumour cells }} & A. unedo & Control \\
\hline & & & $\begin{array}{l}G I_{50} \\
(\mu \mathrm{g} / \mathrm{mL})\end{array}$ & $\begin{array}{l}G I_{50} \\
(\mu \mathrm{g} / \mathrm{mL})\end{array}$ \\
\hline \multicolumn{3}{|c|}{ PLP 2 (porcine liver primary cells) } & $>400$ & $3.2 \pm 0.7$ \\
\hline \multirow{2}{*}{$\begin{array}{c}\text { Antibacterial } \\
\text { activity }\end{array}$} & \multicolumn{2}{|c|}{ A. unedo extract } & \multicolumn{2}{|c|}{ Control (Ampicillin) } \\
\hline & $\begin{array}{l}M I C \\
(\mu \mathrm{g} / \mathrm{mL})\end{array}$ & $\begin{array}{l}M B C \\
(\mu \mathrm{g} / \mathrm{mL})\end{array}$ & $\begin{array}{l}\text { MIC } \\
(\mu \mathrm{g} / \mathrm{mL})\end{array}$ & $\begin{array}{l}M B C \\
(\mu \mathrm{g} / \mathrm{mL})\end{array}$ \\
\hline \multicolumn{5}{|l|}{ Gram negative bacteria } \\
\hline Escherichia coli & $>1000$ & $>1000$ & 400 & 500 \\
\hline Salmonella enteritidis & 150 & 300 & 300 & 600 \\
\hline $\begin{array}{l}\text { Salmonella } \\
\text { typhimurium }\end{array}$ & 200 & 300 & 400 & 750 \\
\hline $\begin{array}{l}\text { Enterobacter cloacae } \\
\text { Gram positive bacteria }\end{array}$ & $>1000$ & $>1000$ & 250 & 500 \\
\hline $\begin{array}{l}\text { Staphylococcus } \\
\text { aureus }\end{array}$ & 300 & 600 & 250 & 450 \\
\hline Bacillus cereus & 150 & 450 & 250 & 400 \\
\hline Micrococcus flavus & 300 & 600 & 250 & 400 \\
\hline $\begin{array}{l}\text { Listeria } \\
\qquad \text { monocytogenes }\end{array}$ & 300 & 600 & 400 & 500 \\
\hline \multirow[t]{2}{*}{ Antifungal activity } & \multicolumn{2}{|c|}{ A. unedo extract } & \multicolumn{2}{|c|}{ Control (Ketoconazole) } \\
\hline & $\begin{array}{l}\text { MIC } \\
(\mu \mathrm{g} / \mathrm{mL})\end{array}$ & $\begin{array}{l}M F C \\
(\mu \mathrm{g} / \mathrm{mL})\end{array}$ & MIC & $M F C$ \\
\hline Aspergillus fumigatus & 150 & 450 & 250 & 500 \\
\hline Aspergillus ochraceus & 200 & 450 & 1500 & 2000 \\
\hline Aspergillus versicolor & 300 & 600 & 200 & 500 \\
\hline $\begin{array}{l}\text { Penicillium } \\
\quad \text { funiculosum }\end{array}$ & 450 & 600 & 200 & 500 \\
\hline $\begin{array}{l}\text { Penicillium } \\
\quad \text { ochrochloron }\end{array}$ & 300 & 600 & 2500 & 3500 \\
\hline Candida crusei & 300 & 600 & 075 & 150 \\
\hline $\begin{array}{l}\text { Penicillium } \\
\quad \text { verrucosum }\end{array}$ & 450 & 600 & 200 & 300 \\
\hline
\end{tabular}

$E C_{50}$ values correspond to the sample concentration achieving $50 \%$ of antioxidant activity or 0.5 of absorbance in the reducing power assay. $G I_{50}$ values correspond to the sample concentration achieving $50 \%$ of growth inhibition in human tumour cell lines or in liver primary culture PLP2. MIC values correspond to the minimal sample concentration that inhibited the bacterial growth; $M B C$ or $M F C$ correspond to the minimum bactericidal or fungicidal concentrations, respectively.

$(\mathrm{kcal})=4 \times(\mathrm{g}$ proteins $+\mathrm{g}$ carbohydrates $)+9 \times(\mathrm{g}$ lipids $)$. Total protein content $(\mathrm{N} \times 5.70)$ was calculated as nitrogen content by the Kjeldahl method, while crude fat relied on the extraction of dried samples with petroleum ether using a Soxhlet apparatus. Finally, the ash content was determined by incineration at $550 \pm 15^{\circ} \mathrm{C}$ (Barros et al., 2013).

- For free sugars analysis, $1.0 \mathrm{~g}$ of dried sample powder was spiked with melezitose as internal standard (IS, $5 \mathrm{mg} / \mathrm{mL}$ ), and extracted with $40 \mathrm{~mL}$ of $80 \%$ aqueous ethanol at $80^{\circ} \mathrm{C}$ for $30 \mathrm{~min}$. The resulting suspension was centrifuged (Centurion K24OR refrigerated centrifuge, West Sussex, UK) at $15,000 \mathrm{~g}$ for $10 \mathrm{~min}$. The supernatant was concentrated at $60{ }^{\circ} \mathrm{C}$ under reduced pressure and defatted three times with $10 \mathrm{~mL}$ of ethyl ether, successively. After concentration at $40^{\circ} \mathrm{C}$, the solid residues were dissolved in water to a final volume of $5 \mathrm{~mL}$ and filtered through $0.2 \mu \mathrm{m}$ Whatman nylon filters. Free sugars were determined in defatted samples by HPLC coupled to a refraction index (RI) detector following a procedure previously described (Caleja et al., 2016). The free sugars were identified by comparison with standards and further quantified considering the internal standard (melezitose) ( $\mathrm{g} / 100 \mathrm{~g}$ of wafers).

- The fat obtained after the Soxhlet extraction was subjected to a methylation process with $5 \mathrm{~mL}$ of methanol: sulfuric acid: toluene 2 : 1: 1 (v: v: v), for $12 \mathrm{~h}$ in a water bath at $50^{\circ} \mathrm{C}$ and $160 \mathrm{rpm}$; then $3 \mathrm{~mL}$ of deionized water was added to obtain phase separation; FAME was recovered by adding $3 \mathrm{~mL}$ of diethyl ether, stirring on a Vortex shaker and passing the upper phase through a micro-column of anhydrous sodium sulfate, in order to eliminate the water. The sample was collected in a vial with Teflon and filtered with a $0.2 \mu \mathrm{m}$ Whatman nylon filter before injection. The fatty acids were determined, by gas chromatography coupled to flame ionization detector (GC-FID), identified by comparison with standards (standard 47885, Sigma-Aldrich, St. Louis, Missouri, USA) and expressed as relative percentages of each fatty acid (Caleja et al., 2016).

- For evaluation of the antioxidant activity, the samples were submitted to DPPH and reducing power assays, described in a previous section (results expressed in $\mathrm{EC}_{50}$ values $\mathrm{mg} / \mathrm{mL}$ ).

\subsubsection{Response evaluation and statistical analysis}

The results were analysed using a Students $t$-student test in order to determine the significant difference between less than three different samples, with $p=0.05$, and this treatment was carried out using the SPSS v. 23.0 program.

\section{Results and discussion}

\subsection{Bioactive properties of the anthocyanins rich extract}

Our research group has previously developed some works using fruits of $A$. unedo due to their traditional uses in the northeast of Portugal. The studies described the antioxidant properties of those fruits as well as the presence of important antioxidant molecules such as tocopherols and carotenoids (Barros, Carvalho, Morais, \& Ferreira, 2010; Guimaraes, Barros, Carvalho, \& Ferreira, 2010). Later, Guimarães et al. (2013) carried out an extensive characterization of the phenolic compounds present in A. unedo fruits and compared the bioactive properties of two different extracts rich in non-anthocyanin phenolic compounds and anthocyanins, respectively (Guimarães et al., 2014). Furthermore, an extraction optimization from these fruits was performed in order to obtain a rich extract in cyanidin-3-O-glucoside (Jiménez et al., 2018). The extract obtained under the optimal point was evaluated in the present study regarding bioactive and colorant simultaneous capacities, as also the conditions that most favoured its stability.

\subsubsection{Antioxidant properties}

There are several techniques that can be used to evaluate the antioxidant activity of pure compounds or complex mixtures (as in the case of plant extracts). In our study, to evaluate the antioxidant activity of $A$. unedo extract, four complementary in vitro assays were selected: DPPH free radicals scavenging, reducing power, $\beta$-carotene bleaching inhibition and TBARS formation inhibition. The results are expressed in $E C_{50}$ values $(\mu \mathrm{g} / \mathrm{mL})$ and summarized in Table 1 . The anthocyanins extract obtained from $A$. unedo fruits showed high antioxidant activity in the 
different assays, mainly in the ability to inhibit TBARS formation with the lowest $E C_{50}$ value. In a recent study, an extract from $A$. unedo rich in catechin was prepared and a high antioxidant activity was also described (Takwa et al., 2018). The reducing power assay was the only method performed that gave a higher antioxidant activity result $\left(E C_{50}\right.$ value $=328 \pm 2 \mu \mathrm{g} / \mathrm{mL}$ ), in comparison with this study; for the remaining assays the present extract revealed a greater antioxidant activity.

\subsubsection{Cytotoxic properties}

The potential effects of natural phenolic compounds as anticancer agents in vitro as well as in vivo has been described in different studies (Carocho \& Ferreira, 2013). Thus, the effects of the extracts on the growth of the four human tumour cell lines (MCF-7, NCI-H460, HeLa, and HepG2) were determined and the values of the $G I_{50}$ (concentrations that caused $50 \%$ of the cell growth inhibition) are detailed in Table 1 . The A. unedo extract rich in cyanidin-3-O-glucoside did not show positive results for NCI-H460, nor HepG2 cell lines $\left(G_{50}>400 \mu \mathrm{g} / \mathrm{mL}\right)$, showing to be able to inhibit the growth of HeLa (cervical carcinoma) and MCF7 (breast carcinoma) cell lines in a moderate way. This extract did not demonstrate cytotoxicity in PLP2 cell lines $\left(G_{50}>400 \mu \mathrm{g} /\right.$ $\mathrm{mL})$. These results are in agreement with the work presented by Ziani et al. (2015), which studied the bioactive properties of infusions prepared from $A$. unedo flowers and leaves (rich in phenolic compounds, such as flavonoids, especially flavonols and phenolic acid esters), describing the absence of cytotoxic effects.

\subsubsection{Antimicrobial properties}

The antimicrobial activity was also studied against a panel of eight bacteria and eight fungi chosen due to their importance in public health. The results obtained for this activity are presented in Table 1 and were divided into antibacterial and antifungal activities. Results are expressed as $M I C$ and $M B C$ or $M F C$ values $(\mu \mathrm{g} / \mathrm{mL})$. The results showed that $A$. unedo extract rich in cyanidin-3-O-glucoside, besides its high antioxidant activity, it also has a high antimicrobial activity. This activity was particularly high against Salmonella enteritidis and Bacillus cereus. Otherwise, the high antifungal activity of the extract was also confirmed, being Aspergillus fumigatus and A. ochraceus the most sensitive fungi, with the lowest MIC and MFC values. The antioxidant and antimicrobial capacities demonstrated by the $A$. unedo extract may be explained by the presence of significant levels of phenolic compounds, such as anthocyanins, as previously demonstrated by Mak, Chuah, Ahmad, and Bhat (2013).

\subsection{Stability of the extracts in aqueous solution systems}

The $A$. unedo extract rich in anthocyanins (mainly cyanidin-3-Oglucoside, Fig. A1) presents a total optimized content of $\sim 500 \mu \mathrm{g} / \mathrm{g}$ of fruit dw or $\sim 800 \mu \mathrm{g} / \mathrm{g}$ of $\mathrm{R}$ extract residue (knowing that the residual extract was $\sim 60 \%$ of the total fruit $d w$ ). Such values can be located within the intermediate values described by other authors in similar plant-based samples. The anthocyanins content varies widely in similar fruit samples, from $\sim 20 \mu \mathrm{g} / \mathrm{g}$ of fruit $\mathrm{dw}$ (plum) (Timberlake and Henry, 1988) to $\sim 15000 \mu \mathrm{g} / \mathrm{g}$ of fruit dw (elderberry) (Clifford, 2000). The achieved results are within the same values as those well-known fruits with high content of anthocyanins such as Nitraria tangutorum Bobr. ( $\sim 650 \mu \mathrm{g} / \mathrm{g}$ of fruit dw) (Sang, Sang, Ma, Hou, \& Li, 2017) and Aristotelia chilensis L. (400 at $1500 \mu \mathrm{g} / \mathrm{g}$ of fruit dw) (Gironés-Vilaplana et al., 2014). Non-controllable variables such as soil properties, sun exposition, harvest time, etc., and controllable variables such as the extraction conditions (time, solvent, temperature, etc.) and techniques (ultrasound, maceration, microwave, etc.), may affect compounds concentration and could increase/decrease the yield efficiencies. However, the higher efficiencies in anthocyanins extraction from $A$. unedo fruits, in comparison with other sources emphasizes the need to perform more detailed evaluations of the stability of the compounds obtained. From the stability point of view, the main factors includes $t$ (Komatsu et al., 2014), pH (Su, Leung, Huang, \& Chen, 2003), T (Demeule et al., 2002), oxygen level (Labbé, Têtu, Trudel, \& Bazinet, 2008) and concentration of other compounds such as antioxidants level, metal ions and other compositional ingredients (Zhu, Zhang, Tsang, Huang, \& Chen, 1997). Although all of these parameters are relevant, most of the authors agree that the essential ones are $t, p H$ and $T$ (Komatsu et al., 2014; Li, Taylor, Ferruzzi, \& Mauer, 2012; Li et al., 2011). Therefore, the stability of anthocyanins content was studied regarding the functions $t, p H$ and $T$ in an aqueous solution system. For all these responses, the stability of the compounds was monitored by HPLC-DAD.

The mathematical analysis of the stability of anthocyanin compounds is first performed from an invariable perspective, fitting each set of conditions of $T$ and $p H$ to the time-dependent model of Eq. (1). Afterwards, the effects caused by the affecting variables $T$ and $p H$ over the time-dependent parametric values of Eq. (1) are depicted and stablished in mathematical terms by auxiliary functions. Then, the mathematical analysis is presented with a global performing fitting analysis from a multivariable perspective. Mathematical analysis using an invariable or multivariable perspective allowed to summarize the response behaviour into parametric information, which helps to perform easier comparisons and predictions. However, the development of models from a multivariable perspective facilitates the possibility of combining the effects of all variables simultaneously into a single master curve that is able to fit all the experimental data (Prieto, Vázquez, \& Murado, 2012a). Such a solution allows to control most factors that affect the system, helping to reduce the over fitted resolutions that perturbs the comprehension of the real effects caused by the variables and therefore, the final parametric values are more reproducible.

\subsubsection{Individual time analysis of each of the conditions of temperature and $\mathrm{pH}$}

The individual time-dependent graphical analysis of the stability of the anthocyanin content in aqueous solution as function of the $p H$ and $T$ are presented in Section A of Figs. 2 and 3. Fig. 2 shows the stability results for the total anthocyanin content, meanwhile Fig. 3 shows the stability of the individual content of the identified anthocyanin compounds of C1 (delphinidin-3-O-glucoside), C2 (cyanidin-3-O-glucoside) and C3 (cyanidin-3-O-pentoside). Each graphical illustration shows the time degradation effects $(0-190 \mathrm{~h})$ of each $T$ tested $(4,25,40,55$, and $\left.70{ }^{\circ} \mathrm{C}\right)$. Points are the experimental data of the different $\mathrm{pHs}$ tested $(\bullet 2$, $\bigcirc 3.5, \diamond 5, \diamond 6.5$ and $\star 8)$ and lines $(-)$ show the results predicted by Eq. (1). The parametric results and correlation coefficients obtained after fitting each kinetic degradation at each of the $T$ and $p H$ values tested by Eq. (1) are presented in Table 2. In all cases the statistical description was significant and the prediction of the anthocyanins content stability in solution by Eq. (1) showed highly consistent $\mathrm{R}^{2}$ values. When observing the patterns of the kinetic parametric values $k$ and $r$ (Table 2), it can be observed that the kinetic parameter value of $k$ remain constant at each value of $T$ and $p H$, meanwhile the kinetic parameter $r$ is the one that takes into account all the effects caused by the changes of $T$ and $p H$.

\subsubsection{Multivariable analysis for the global comprehension of the anthocyanins stability}

To be able to describe those effects in a multivariate form, the degradation rate parameter of Eq. (1) ( $r$ ) assumes all the perturbation effects caused by the $p H$ and $T$ variables. The increase in $p H$ and $T$ units causes an exponential increase on the degradation rate of the stability of anthocyanin compounds. The $T$ effect behaves following the Arrhenius equation presented in Eq. (2). However, the $p H$ effect cannot be described by any standard physical-chemical function, because the main mechanisms behind the $p H$ in basic chemical reactions or complex living organisms are dissimilar and heterogeneous. For this particular 


\section{A: INDIVIDUAL ANALYSIS}

$$
\text { อ }
$$

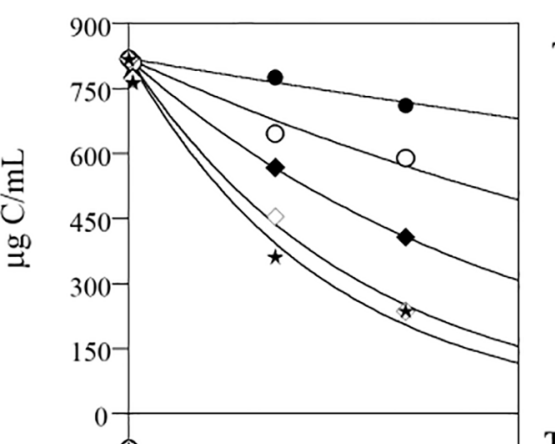

$\mathrm{T}=4^{\circ} \mathrm{C}$
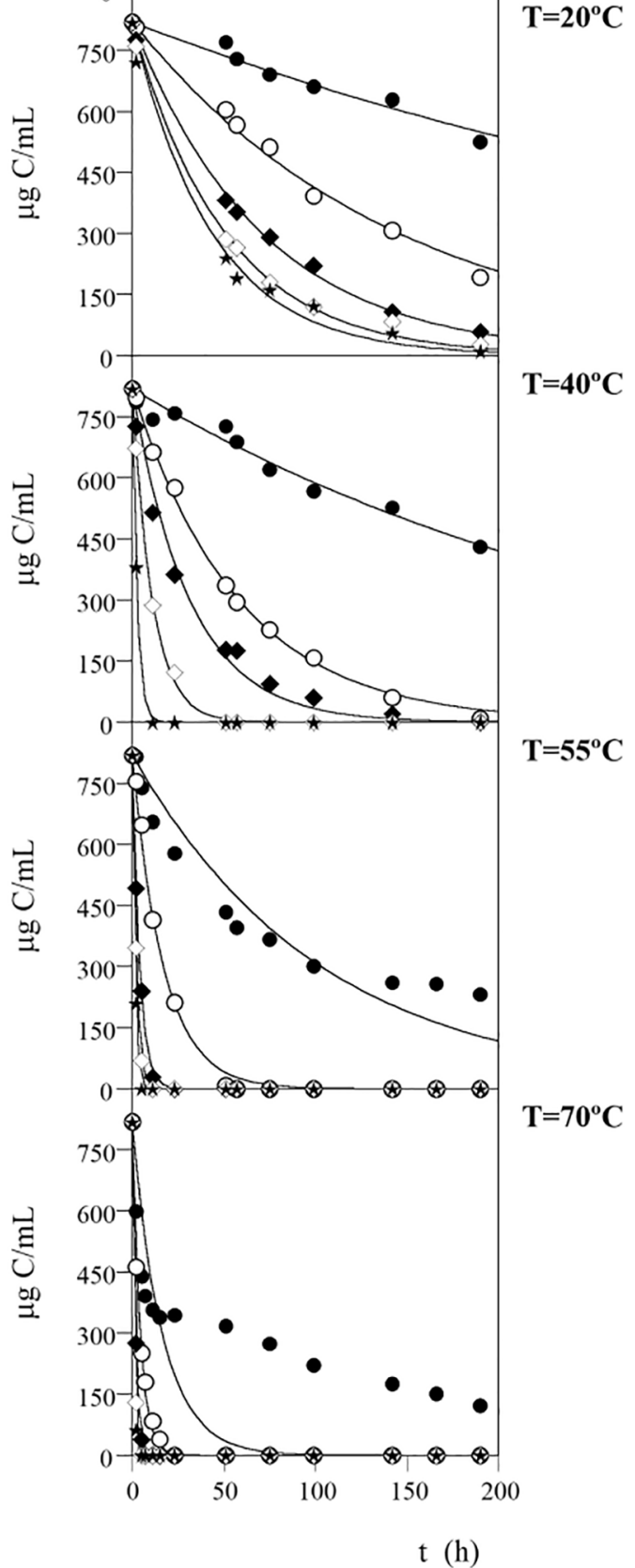

B: MULTIVARIABLE ANALYSIS

\section{B1: Parametric pattern}

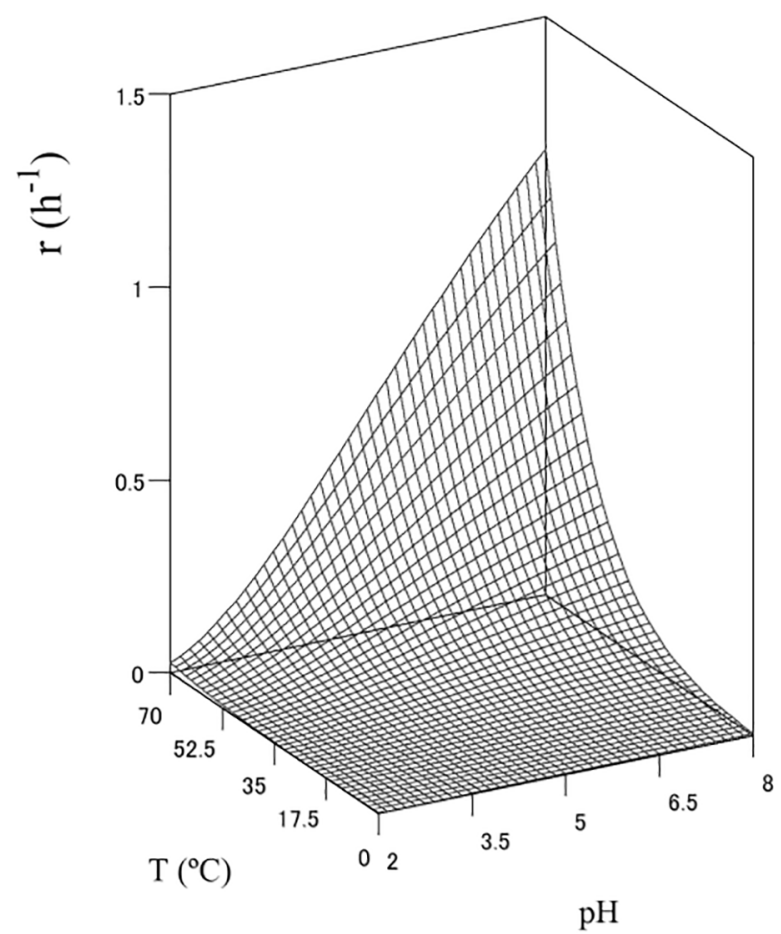

B2: Experimental data and modelled

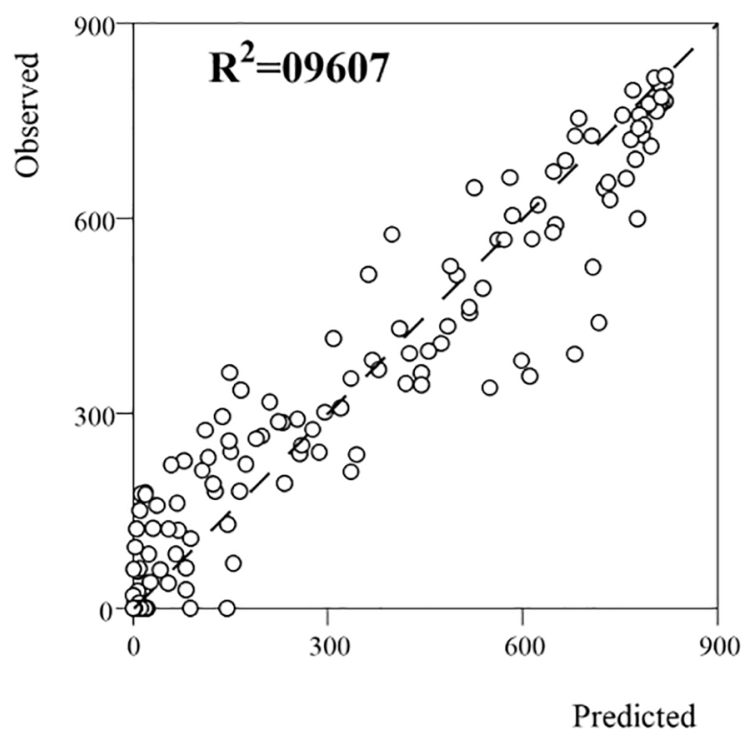

(caption on next page) 


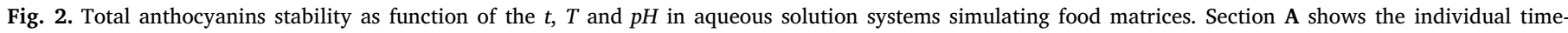

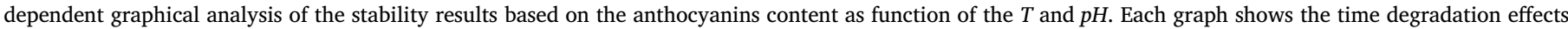

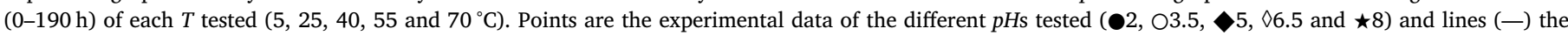

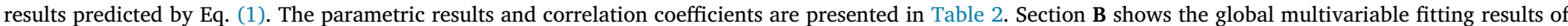

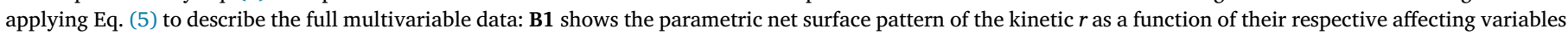
( $\mathrm{pH}$ and T); and B2 shows the correlation between the experimental values and the predicted ones obtained with the multivariable model presented in Eq. (5).

C1

\section{A: INDIVIDUAL}

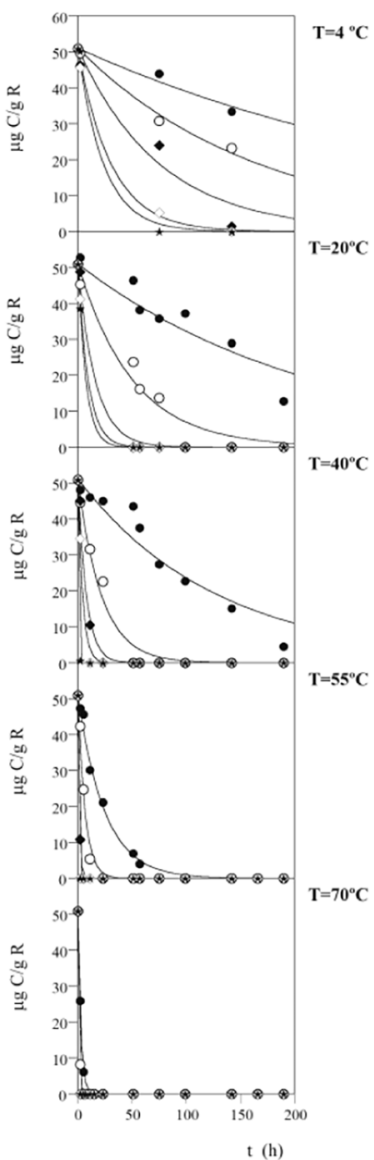

B: MULTIVARIABLE

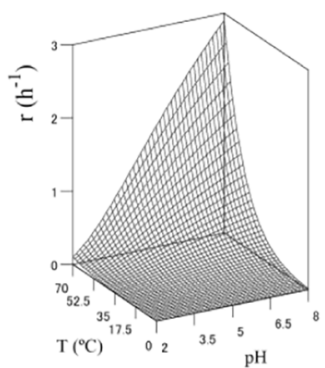

C2

A: INDIVIDUAL

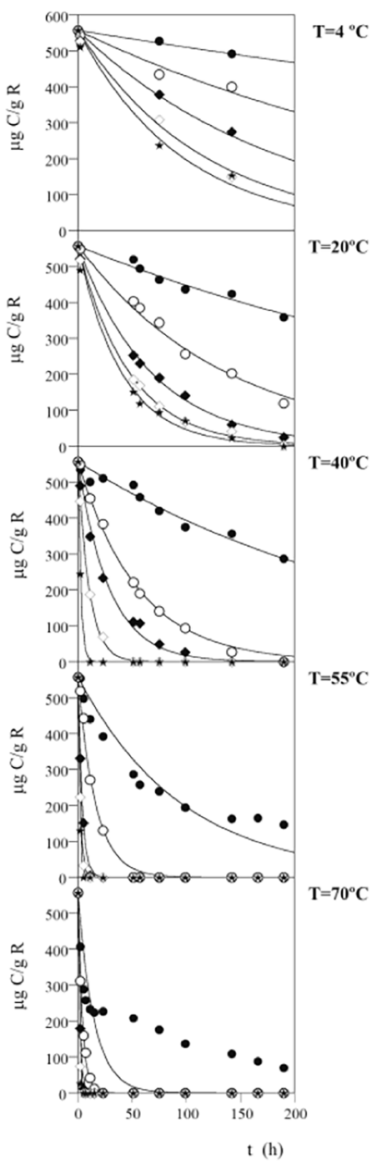

B: MULTIVARIABLE

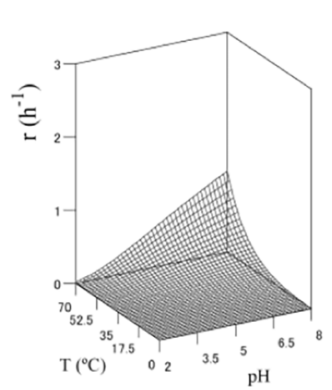

C3

A: INDIVIDUAL

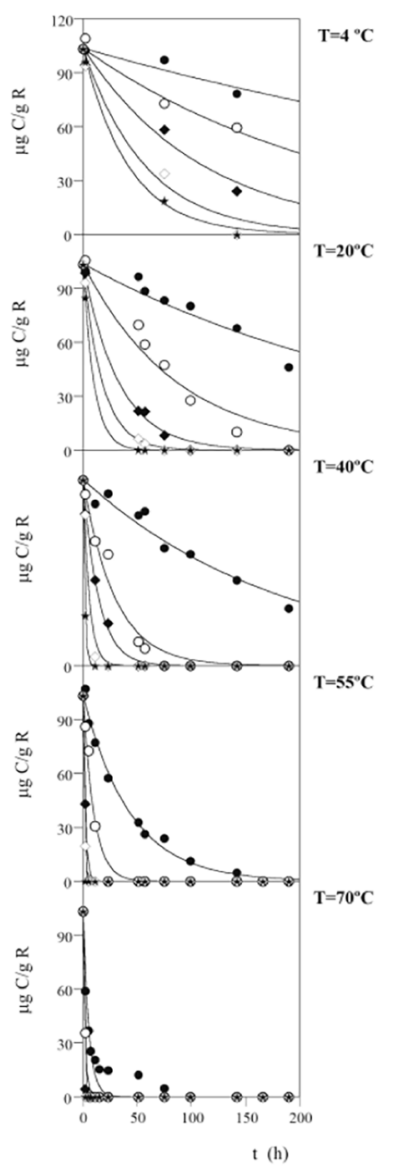

B: MULTIVARIABLE

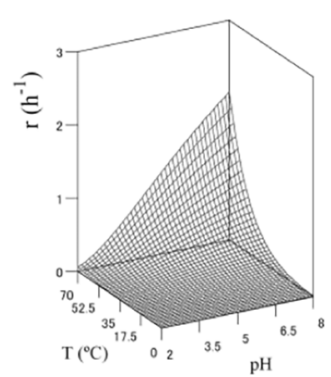

Fig. 3. Individual stability of delphinidin-3-O-glucoside (C1), cyanidin-3-O-glucoside (C2) and cyanidin-3-O-pentoside (C3) as function of the $t$, $T$ and $p H$ in aqueous solution systems simulating food matrices. Two sub- sections for each compound are represented as in Fig. 2. Section A shows the individual time-dependent graphical analysis of the stability results based on the anthocyanins content as function of the $T$ and $p H$. Each graph shows the time degradation effects ( $0-190 \mathrm{~h})$ of each $T$ tested $\left(5,25,40,55\right.$ and $\left.70^{\circ} \mathrm{C}\right)$. Points are the experimental data of the different $p H$ s tested $(\bullet 2, \bigcirc 3.5, \diamond 5, \diamond 6.5$ and $\star 8)$ and lines $(-)$ the results predicted by Eq. (1). The parametric results and correlation coefficients are presented in Table 2. Section B shows the global multivariable fitting results of applying Eq. (5) to describe the full multivariable data of the parametric net surface pattern of the kinetic $r$ as a function of their respective affecting variables ( $p H$ and $T$ ). 


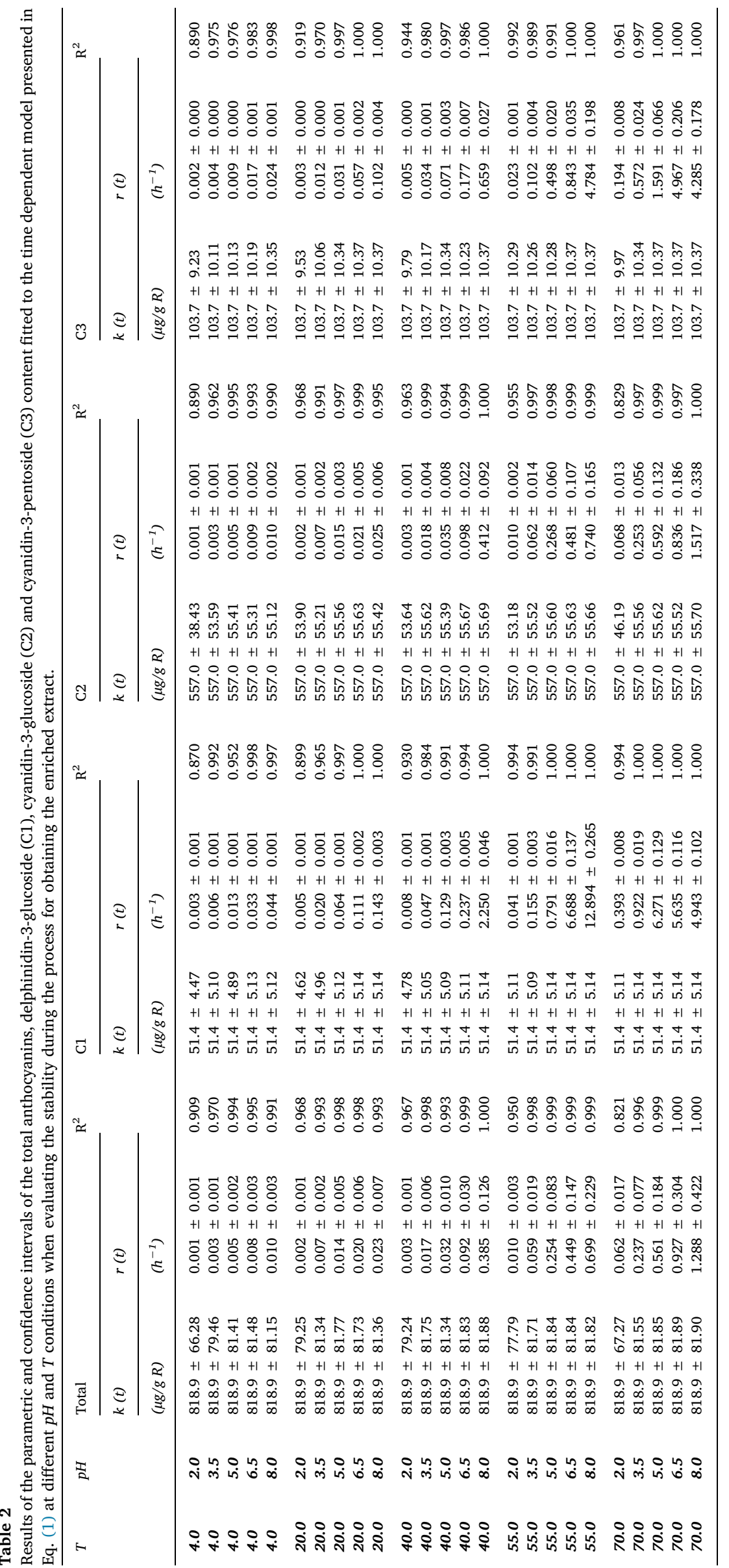


case, the $p H$ effect follows a positive exponential relation as described by Eq. (3). Therefore, the general solution presented in Eq. (4) is reduced to a simpler solution in which only the kinetic parameter $r$ is assuming the effects caused by the variables. In conclusion, the global multivariable model that controls the effect of $t, p H$ and $T$ on the stability in aqueous system can be established by substituting the $r$ parameter of Eq. (1) with the equations leading the effect of the variables $T$ (Eq. (2)) and the $p H$ (Eq. (3)), as follows:

$e(t, p H, T)=k \exp \left(-p \exp \left(-\frac{E a}{R T}+b p H\right) t\right)$

When substituting the $r$ parameter by the multiplicative results of Eqs. (2) and (3), the new resulting expression share a pre-exponential factor ( $A$ and $s$ ) and their use in conjunction will be redundant therefore, a new factor is described and noted as $p$. All other parametric notations are as defined in the material and methods section. Section B of Figs. 2 and 3 show the global multivariable fitting results of applying Eq. (5) to describe the full multivariable data.

The parametric results for the different multivariable analysis are:

- The resulting parameters of the total anthocyanin content analysis were $k=819.00 \pm 56.1 \mu \mathrm{g} / \mathrm{g} \mathrm{R}, \quad p=59.32 \pm 11.2$, $E a=4.35 \times 10^{+9} \pm 0.98 \times 10^{+9} \mathrm{~kJ}$ and $b=10.05 \pm 3.5$ obtaining a $\mathrm{R}^{2}$ values of 0.9577 .

- For $\mathrm{C} 1$ were $k=50.16 \pm 4.3 \mu \mathrm{g} / \mathrm{g} \quad \mathrm{R}, \quad p=57.10 \pm 9.7$, $E a=4.35 \times 10^{+9} \pm 1.21 \times 10^{+9} \mathrm{~kJ}$ and $b=8.91 \pm 2.3 \mathrm{ob}-$ taining a $\mathrm{R}^{2}$ values of 0.9396 .

- For C2 were $k=527.35 \pm 116.4 \mu \mathrm{g} / \mathrm{g} \quad \mathrm{R}, \quad p=59.38 \pm 7.8$, $E a=4.35 \times 10^{+9} \pm 0.46 \times 10^{+9} \mathrm{~kJ}$ and $b=10.23 \pm 3.2 \mathrm{ob}-$ taining a $\mathrm{R}^{2}$ values of 0.9590 .

- For C3 were $k=101.20 \pm 31.4 \mu \mathrm{g} / \mathrm{gR}, \quad p=57.95 \pm 7.6$, $E a=4.35 \times 10^{+9} \pm 0.44 \times 10^{+9} \mathrm{~kJ}$ and $b=9.42 \pm 3.5$ obtaining a $\mathrm{R}^{2}$ values of 0.9534 .

In all cases the statistical description was significant and the prediction of the anthocyanin content stability in solution by Eq. (5) showed highly consistent $\mathrm{R}^{2}$ values. The multivariable analysis of the kinetic parameter $r$ as a function of their respective affecting variables ( $p H$ and $T$ ) presented in the subsection B of Figs. 2 and 3, show the 3D graphical surface response for the degradation rate of the total anthocyanins content and for the individual content of the identified anthocyanin compounds ( $\mathrm{C} 1, \mathrm{C} 2$ and $\mathrm{C} 3$ ). The conclusions are in accordance with previous results reported (Komatsu et al., 2014; Li et al., 2012; Li et al., 2011), revealing that at $T<20^{\circ} \mathrm{C}$ and $p H<3.5$ the extract is more stable lowering as much as possible the degradation rate of anthocyanin compounds.

In the aqueous solution system, it proved to be highly dependent on the three variables studied. Compounds decayed completely over a period of time at different $p H$ and $T$. This phenomenon was also detected by other authors that studied the stability of catechin and derivatives from other matrices such as green tea and cacao (Komatsu et al., 2014; Li et al., 2012; Zhu et al., 2002, Zhu et al., 1997). In similar terms with other authors (Li et al., 2012), results indicated that anthocyanin extracts in aqueous solution remained stable at a $p H$ value lower than 3.5 and temperatures below $30^{\circ} \mathrm{C}$ for a period of $72 \mathrm{~h}$. Even at high thermal process conditions $\left(70^{\circ} \mathrm{C}\right.$ ) with a $p H$ lower than 3.5 , the anthocyanins content is detected during $1 \mathrm{~h}$ period without great losses. These results may limit the anthocyanin extract direct application, favouring acid foods as some chesses, fruit juice, vegetable/fruit products, mayonnaises and yogurts.

The key issue lies down behind the fact that anthocyanins undergo kinetic degradation during thermal processing and that the increase of the $p H$ causes molecular changes in detriment of its colour properties (Komatsu et al., 2014; Ruiz-Rodríguez et al., 2011). The analytical solution of such a system through mathematical models is important and necessary, but not exempt of complexity due to the heterogeneous responses of the variables involved. Achieving a successful mathematical model solution would allow to control most factors that affect the system, helping to standardize the key variables for producing stable plant-based extracts and therefore, to optimize the complete extraction process.

The analysis of the anthocyanin compounds stability from the strawberry tree fruits is crucial for predicting the shelf life behaviour of the compounds in various processing situations. In fact, food processing or other processes are factors that affect directly on the integrity of the molecules. Controlling the conditions of $t, p H$ and $T$ among others are essential aspects for keeping the process efficiency and for obtaining high quality products. Mathematical models were developed and multiple graphical plots were conducted to establish and illustrate the optimum values of the independent variables studied. Thus, the kinetic models could be used for calculating shelf-life and predicting compounds stability at given $p H$ and $T$ conditions for aqueous systems. The optimal stability conditions for anthocyanins content in aqueous solution remained intact at $p H<3.5$ and $T<30^{\circ} \mathrm{C}$ for a period of at least $72 \mathrm{~h}$. Moreover, using the optimal processing conditions, it is possible to produce functional extracts with high potential as nutraceuticals or as active ingredients in the design of functional foods, which can be also extended to other industrial fields such as pharmaceutical and cosmeceutical industries.

\subsection{Incorporation of the anthocyanins rich extract as a natural colorant} additive in wafers: Colour parameters, $\mathrm{pH}$, nutritional composition and antioxidant activity of the samples along storage time

The bakery industry represents an important economic sector and is currently in great growth and constant innovation. Wafers are wellknown cakes and consumed worldwide. Thus, their preparation using natural colorants instead of artificial ones, is a representative case study for the bakery sector. However, it is important to evaluate the colour changes caused in the food matrix within the storage time, as well as the effects in other parameters such as $\mathrm{pH}$, nutritional composition and the preservative function, evaluated using antioxidant activity assays.

Part A of Table 3 shows the result values obtained for each of the evaluated colour parameter $\left(L^{*}, a^{*}\right.$ and $\left.b^{*}\right)$ in each one of the food samples during the storage period (6 days). The results presented in Table 3 (part A) demonstrate that the incorporation of $A$. unedo extract rich in cyanidin-3-O-glucoside caused slight changes in the wafers when compared to the control wafer, along the different storage time. In visual terms, the $A$. unedo extract provides a slightly golden colour to the wafer (Fig. 1, sub-Fig. 3.a) when compared to the control wafer (Fig. 1, sub-Fig. 3.b). These results are in accordance with those produced by other authors (Debonne, Van Bockstaele, Philips, De Leyn, \& Eeckhout, 2017), when evaluating the colorimetric parameters in pastry and baking products, revealing that it is necessary to consider that the colour of the crust is directly related to the temperature and cooking time and not entirely related to the products used.

- Parts B, C, D and E of Table 3 show the $p H$ values, macronutrients content, individual sugar contents and energy of the control wafers and of the wafers whit the $A$. unedo extract rich in cyanidin-3-Oglucoside during the self-life period of the product. As a bakery product which has been baked with temperature, moisture values (Table 3) were expected to be quite low. It is possible to verify that the carbohydrates are the most abundant macronutrients in wafers. The results show that the incorporation of the extract did not cause significant changes in relation to the control sample, for all the studied storage times. Three individual sugars were detected in the samples: fructose, glucose and sucrose (Fig. A1), with a high prevalence of the disaccharide. Significant differences were detected only for fructose and glucose after 3 and 6 days of storage, whereas the wafers incorporated with the extract always showed higher amounts of these sugars when compared to the control wafers. This 
Table 3

Results of colour parameters, $\mathrm{pH}$, nutritional composition, free sugars, fatty acids and antioxidant activity of wafer samples.

\begin{tabular}{|c|c|c|c|c|c|c|c|c|c|c|}
\hline \multirow[t]{2}{*}{ Parameters } & \multicolumn{4}{|l|}{0 Days } & \multicolumn{3}{|l|}{3 Days } & \multicolumn{3}{|l|}{6 Days } \\
\hline & & Control & $\mathrm{AU}$ & $t$-test & Control & $\mathrm{AU}$ & $t$-test & Control & $\mathrm{AU}$ & $t$-test \\
\hline \multicolumn{11}{|c|}{ A) Colour parameters } \\
\hline$L^{*}$ & & $52.6 \pm 0.6$ & $52 \pm 1$ & 0.91 & $50.0 \pm 0.4$ & $54 \pm 2$ & 0.191 & $50.5 \pm 0.4$ & $54 \pm 2$ & 0.341 \\
\hline$a^{*}$ & & $18.1 \pm 0.5$ & $16 \pm 1$ & 0.168 & $19.5 \pm 0.1$ & $15.3 \pm 0.5$ & 0.005 & $18.2 \pm 0.5$ & $15.6 \pm 0.4$ & 0.02 \\
\hline$b^{*}$ & & $36.8 \pm 0.7$ & $35 \pm 1$ & 0.149 & $36.1 \pm 0.6$ & $38 \pm 1$ & 0.114 & $35.1 \pm 0.5$ & $36 \pm 1$ & 0.533 \\
\hline \multicolumn{11}{|l|}{ B) $p H$ value } \\
\hline$p H$ & & $5.64 \pm 0.09$ & $5.3 \pm 0.1$ & 0.009 & $5.58 \pm 0.04$ & $5.7 \pm 0.3$ & 0.329 & $5.48 \pm 0.06$ & $5.9 \pm 0.5$ & 0.185 \\
\hline \multicolumn{11}{|c|}{ C) Nutritional composition } \\
\hline Moisture & $(\mathrm{g} / 100 \mathrm{~g} \mathrm{fw})$ & $11.42 \pm 0.08$ & $11.25 \pm 0.09$ & 0.058 & $11.5 \pm 0.2$ & $11.9 \pm 0.1$ & 0.054 & $11.4 \pm 0.2$ & $10.9 \pm 0.1$ & 0.018 \\
\hline Ash & $(g / 100 \mathrm{~g} \mathrm{fw})$ & $0.018 \pm 0.01$ & $0.018 \pm 0.01$ & 0.682 & $0.020 \pm 0.01$ & $0.017 \pm 0.01$ & 0.205 & $0.017 \pm 0.01$ & $0.018 \pm 0.01$ & 0.396 \\
\hline Fat & $(\mathrm{g} / 100 \mathrm{~g} \mathrm{fw})$ & $21.7 \pm 0.5$ & $22.5 \pm 0.1$ & 0.044 & $22.6 \pm 0.7$ & $21.5 \pm 0.9$ & 0.17 & $22.4 \pm 0.2$ & $21.7 \pm 0.2$ & 0.026 \\
\hline Proteins & $(\mathrm{g} / 100 \mathrm{~g} \mathrm{fw})$ & $9.6 \pm 0.3$ & $9.48 \pm 0.09$ & 0.388 & $8.47 \pm 0.07$ & $9.0 \pm 0.2$ & 0.005 & $9.45 \pm 0.5$ & $9.0 \pm 0.1$ & 0.096 \\
\hline Total sugars & $(\mathrm{g} / 100 \mathrm{~g} \mathrm{fw})$ & $57.3 \pm 0.4$ & $56.8 \pm 0.1$ & 0.123 & $57.4 \pm 0.6$ & $57.6 \pm 0.8$ & 0.764 & $56.8 \pm 0.4$ & $58.3 \pm 0.2$ & 0.002 \\
\hline Energy & (kcal/100 g fw) & $463 \pm 2$ & $467 \pm 1$ & 0.027 & $467 \pm 3$ & $460 \pm 4$ & 0.099 & $466 \pm 1$ & $465 \pm 1$ & 0.203 \\
\hline \multicolumn{11}{|l|}{ D) Free sugars } \\
\hline Fructose & $(g / 100 g$ fw) & $0.32 \pm 0.01$ & $0.64 \pm 0.09$ & 0.001 & $0.35 \pm 0.01$ & $0.76 \pm 0.003$ & $<0.001$ & $0.33 \pm 0.01$ & $0.69 \pm 0.001$ & $<0.001$ \\
\hline Glucose & $(\mathrm{g} / 100 \mathrm{~g} \mathrm{fw})$ & $0.38 \pm 0.01$ & $0.51 \pm 0.06$ & 0.005 & $0.39 \pm 0.02$ & $0.58 \pm 0.004$ & $<0.001$ & $0.31 \pm 0.02$ & $0.53 \pm 0.003$ & $<0.001$ \\
\hline Sucrose & $(g / 100 g$ fw $)$ & $28.1 \pm 0.2$ & $28.3 \pm 0.9$ & 0.702 & $28.4 \pm 0.4$ & $29.2 \pm 0.7$ & 0.06 & $28.17 \pm 0.07$ & $30.0 \pm 0.7$ & 0.004 \\
\hline Total & $(g / 100 g$ fw $)$ & $28.8 \pm 0.2$ & $29 \pm 1$ & 0.216 & $29.1 \pm 0.4$ & $30.6 \pm 0.7$ & 0.011 & $28.82 \pm 0.05$ & $31.2 \pm 0.7$ & 0.001 \\
\hline \multicolumn{11}{|l|}{ E) Fatty acids } \\
\hline $\mathrm{C} 12: 0$ & $(\%)$ & $3.3 \pm 0.1$ & $3.22 \pm 0.09$ & 0.332 & $3.1 \pm 0.2$ & $3.21 \pm 0.07$ & 0.234 & $3.28 \pm 0.08$ & $3.3 \pm 0.1$ & 0.728 \\
\hline C14:0 & $(\%)$ & $1.65 \pm 0.03$ & $1.65 \pm 0.02$ & 0.898 & $1.59 \pm 0.06$ & $1.63 \pm 0.03$ & 0.322 & $1.68 \pm 0.03$ & $1.67 \pm 0.03$ & 0.851 \\
\hline C16:0 & $(\%)$ & $30.8 \pm 0.4$ & $30.8 \pm 0.4$ & 0.942 & $29.8 \pm 0.3$ & $30.5 \pm 0.5$ & 0.073 & $31.4 \pm 0.4$ & $31.4 \pm 0.5$ & 0.839 \\
\hline C18:0 & $(\%)$ & $30.9 \pm 0.3$ & $31.6 \pm 0.1$ & 0.042 & $30.8 \pm 0.5$ & $31 \pm 1$ & 0.736 & $29.9 \pm 0.5$ & $31.0 \pm 0.5$ & 0.055 \\
\hline C18:2n6 & $(\%)$ & $30.4 \pm 0.2$ & $29.7 \pm 0.3$ & 0.036 & $31.9 \pm 0.5$ & $31.3 \pm 0.4$ & 0.121 & $30.9 \pm 0.2$ & $29.8 \pm 0.4$ & 0.021 \\
\hline C18:3n3 & $(\%)$ & $1.28 \pm 0.04$ & $1.37 \pm 0.02$ & 0.053 & $1.30 \pm 0.03$ & $1.25 \pm 0.09$ & 0.459 & $1.376 \pm 0.01$ & $1.30 \pm 0.09$ & 0.236 \\
\hline SFA & $(\%)$ & $67.9 \pm 0.2$ & $68.5 \pm 0.3$ & 0.046 & $66.4 \pm 0.5$ & $67.1 \pm 0.4$ & 0.138 & $67.4 \pm 0.2$ & $68.5 \pm 0.5$ & 0.03 \\
\hline MUFA & $(\%)$ & $0.34 \pm 0.03$ & $0.38 \pm 0.01$ & 0.162 & $0.35 \pm 0.01$ & $0.39 \pm 0.01$ & 0.024 & $0.34 \pm 0.04$ & $0.38 \pm 0.01$ & 0.19 \\
\hline PUFA & $(\%)$ & $31.7 \pm 0.2$ & $31.1 \pm 0.3$ & 0.041 & $33.2 \pm 0.5$ & $32.5 \pm 0.4$ & 0.125 & $32.2 \pm 0.2$ & $31.1 \pm 0.5$ & 0.027 \\
\hline \multicolumn{11}{|c|}{ F) Antioxidant activity } \\
\hline DPPH activity & $(\mathrm{mg} / \mathrm{mL})$ & $>200$ & $43.3 \pm 0.6$ & $<0.001$ & $>200$ & $43.5 \pm 0.5$ & $<0.001$ & $>200$ & $57 \pm 1$ & $<0.001$ \\
\hline Reducing power & $(\mathrm{mg} / \mathrm{mL})$ & $15.0 \pm 0.4$ & $14 \pm 0.1$ & $<0.001$ & $21.7 \pm 0.8$ & $14.42 \pm 0.20$ & $<0.001$ & $23.9 \pm 0.3$ & $15.9 \pm 0.4$ & $<0.001$ \\
\hline
\end{tabular}

Control- wafer without extract and AU- wafers with $A$. unedo extract rich in cyanidin-3-O-glucoside. In each line and for each storage time a Students $t$-test was used to determine the significant difference between two different samples, with $\alpha=0.05 . L^{*}, a^{*}$ and $b^{*}$ represent colour parameters. SFA- Saturated fatty acids; MUFAMonounsaturated fatty acids; PUFA- Polyunsaturated fatty acids. Antioxidant activity was evaluated in terms of $\mathrm{EC}_{50}$ values that correspond to the sample concentration achieving $50 \%$ of antioxidant activity or 0.5 of absorbance in reducing power assay.

fact may be related with the presence of free sugars in the $A$. unedo extract.

- Table 3E shows the six most abundant fatty acids detected in wafer samples. Although fourteen fatty acids were identified in the studied samples (Fig. A1), eight were detected only in trace amounts (data not shown). The most abundant fatty acids were palmitic acid (C16:0), stearic acid (C18:0) and linoleic acid (C18:2n6). In this work, it was verified that the saturated fatty acids appear in higher quantity than the unsaturated counterparts, and the incorporation of the extract did not cause significant changes in the fatty acids profile when compared to the control wafers at any storage period. The amount of extract added was in a low amount and as such it would be expected that no changes are made to the fatty acid profile of the wafers, since the shelf life was very short and therefore over time there were also no changes.

- Finally, the antioxidant activity results (preservation potential of the extract rich in anthocyanins) based on the DPPH radical scavenging activity and reducing power of the wafers samples during the shelflife period are presented in Table 3F. The incorporation of the extract obtained from $A$. unedo and rich in cyanidin-3-O-glucoside provides significantly beneficial properties to the tested food matrix as compared to the control wafers. This is in agreement with the results obtained in previous studies where chestnut flowers were incorporated into "económicos" cakes (Carocho et al., 2015), aqueous extracts of fennel and chamomile in cookies (Caleja, Barros, Antonio, Oliveira, \& Ferreira, 2017) and in a study using a catechinrich extract obtained from $A$. unedo incorporated into bread (Takwa et al., 2018). In general, it was concluded that the incorporation of these natural ingredients introduces beneficial properties to the tested food products.

As demonstrated in other studies involving natural extracts with the aim of replacing artificial additives (Carocho et al., 2015; Caleja, et al., 2017), the key lies down behind the preservation of the beneficial properties of the extracts without altering the organoleptic characteristics of the original product. Therefore, as a function of the results presented in Table 3, the extract from $A$. unedo rich in cyanidin-3-Oglucoside is able to provide colorant properties with functional antioxidant properties without altering the main organoleptic characteristics of the food sample, demonstrating the potential of $A$. unedo fruit extracts for industrial applications.

\section{Conclusions}

There are no productive applications found at an industry level for the fruits of Arbutus unedo L. (Ericaceae family), because this plant is mainly used as an ornamental plant. Spontaneous growth by seedlings are found along the Mediterranean region easily. Most of the fruit production is discarded, because it only reaches a pleasant flavour during a short period of time and only minor traditional uses have been described (jams, wines and liqueurs). The edible reddish sweet fruit produced contains a diverse source of health promoting compounds, such as tocopherols, carbohydrates, sugars, and phenolic compounds. Additionally, given the evidence that the fruits contain a good amount 
of anthocyanins, and also that this raw material is easy to obtain in good quantities in the areas where they are abundant, it may be interesting to use them as a new source of anthocyanins, which contributes, favours and promotes the use of these compounds as a natural colorant. Therefore, valorising, producing added-value extract rich in anthocyanins and understanding the stability patterns of this compounds with interest for the food technology field, from this underused fruit, could be of interest for the industrial sector and research community.

The present results provide information for: i) potential industrial application of extracts from $A$. unedo fruits, as alternative source of anthocyanins to be used as natural colorant ingredients with bioactive properties; ii) shelf-life predictions of the extract rich in anthocyanins (mainly cyanidin-3-O-glucoside) at specific conditions of temperature and $\mathrm{pH}$. Overall, the incorporation of the $A$. unedo extract gave a more attractive colour to the wafers and improved the antioxidant activity, without causing significant changes in the nutritional profile of the wafers.

\section{Acknowledgements}

The authors are grateful to the Foundation for Science and Technology (FCT, Portugal) and FEDER under Programme PT2020 for financial support to CIMO (UID/AGR/00690/2013), L. Barros contract and C. Caleja (SFRH/BD/93007/2013) grant. This work is funded by the European Regional Development Fund (ERDF) through the Regional Operational Program North 2020, within the scope of Project NORTE01-0145-FEDER-023289: DeCodE and project Mobilizador Norte-010247-FEDER-024479: ValorNatural ${ }^{\circledR}$. The authors are also grateful to FEDER-Interreg España-Portugal programme for financial support through the project 0377_Iberphenol_6_E. To Xunta de Galicia for financial support for the post-doctoral researcher of M.A. Prieto.

\section{Appendix A. Supplementary data}

Supplementary data to this article can be found online at https:// doi.org/10.1016/j.foodchem.2018.09.099.

\section{References}

AOAC International. (2016). Official methods of analysis of AOAC International. In W. Dr. George \& J. Latimer (Eds.). (20th ed.).

Barros, L., Carvalho, A. M., Morais, J. S., \& Ferreira, I. C. F. R. (2010). Strawberry-tree, blackthorn and rose fruits: Detailed characterisation in nutrients and phytochemicals with antioxidant properties. Food Chemistry, 120(1), 247-254.

Barros, L., Dueñas, M., Dias, M. I., Sousa, M. J., Santos-Buelga, C., \& Ferreira, I. C. F. R. (2013). Phenolic profiles of cultivated, in vitro cultured and commercial samples of Melissa officinalis L. infusions. Food Chemistry, 136(1), 1-8.

Caleja, C., Barros, L., Antonio, A. L., Carocho, M., Oliveira, M. B. P. P., \& Ferreira, I. C. F. R. (2016). Fortification of yogurts with different antioxidant preservatives: A comparative study between natural and synthetic additives. Food Chemistry, 210, $262-268$.

Caleja, C., Barros, L., Antonio, A. L., Oliveira, M. B. P. P., \& Ferreira, I. C. F. R. (2017). A comparative study between natural and synthetic antioxidants: Evaluation of their performance after incorporation into biscuits. Food Chemistry, 216, 342-346.

Carocho, M., Barreira, J. C. M., Barros, L., Bento, A., Cámara, M., Morales, P., \& Ferreira, I. C. F. R. (2015). Traditional pastry with chestnut flowers as natural ingredients: An approach of the effects on nutritional value and chemical composition. Journal of Food Composition and Analysis, 44, 93-101.

Carocho, M., Barreiro, M. F., Morales, P., \& Ferreira, I. C. F. R. (2014). Adding molecules to food, pros and cons: A review on synthetic and natural food additives. Comprehensive Reviews in Food Science and Food Safety, 13(4), 377-399.

Carocho, M., \& Ferreira, I. C. F. R. (2013). The role of phenolic compounds in the fight against cancer-a review. Anti-Cancer Agents in Medicinal Chemistry, 13(8), $1236-1258$.

Cavalcanti, R. N., Santos, D. T., \& Meireles, M. A. A. (2011). Non-thermal stabilization mechanisms of anthocyanins in model and food systems-An overview. Food Research International, 44(2), 499-509.

Cevallos-Casals, B. A., \& Cisneros-Zevallos, L. (2004). Stability of anthocyanin-based aqueous extracts of Andean purple corn and red-fleshed sweet potato compared to synthetic and natural colorants. Food Chemistry, 86(1), 69-77.

Clifford, M. N. (2000). Anthocyanins - nature, occurrence and dietary burden. Journal of the Science of Food and Agriculture, 80(7), 1063-1072.
Debonne, E., Van Bockstaele, F., Philips, E., De Leyn, I., \& Eeckhout, M. (2017). Impact of par-baking and storage conditions on the quality of par-baked and fully baked bread. LWT - Food Science and Technology, 78, 16-22.

Demeule, M., Michaud-Levesque, J., Annabi, B., Gingras, D., Boivin, D., Jodoin, J., Béliveau, R. (2002). Green tea catechins as novel antitumor and antiangiogenic compounds. Current Medicinal Chemistry. Anti-Cancer Agents, 2, 441-463.

Ding, M., Feng, R., Wang, S. Y., Bowman, L., Lu, Y., Qian, Y., ... Shi, X. (2006). Cyanidin3-glucoside, a natural product derived from blackberry, exhibits chemopreventive and chemotherapeutic activity. Journal of Biological Chemistry, 281(25), 17359-17368.

Esatbeyoglu, T., Wagner, A. E., Schini-Kerth, V., \& Rimbach, G. (2015). Betanin-A food colorant with biological activity. Molecular Nutrition and Food Research, 59(1), 36-47.

Garzón, G. A. (2008). Las antocianinas como colorantes naturales y compuestos bioactivos: Revisión. Acta Biológica Colombiana, 13(3), 27-36.

Ge, Q., \& Ma, X. (2013). Composition and antioxidant activity of anthocyanins isolated from Yunnan edible rose (An ning). Food Science and Human Wellness, 2(2), 68-74.

Gironés-Vilaplana, A., Baenas, N., Villaño, D., Speisky, H., García-Viguera, C., \& Moreno, D. A. (2014). Evaluation of Latin-American fruits rich in phytochemicals with biological effects. Journal of Functional Foods, 7(1), 599-608.

Guimarães, R., Barros, L., Calhelha, R. C., Carvalho, A. M., Queiroz, M. J. R. P., \& Ferreira, I. C. F. R. (2014). Bioactivity of different enriched phenolic extracts of wild fruits from Northeastern Portugal: A comparative study. Plant Foods for Human Nutrition, 69(1), 37-42.

Guimaraes, R., Barros, L., Carvalho, A. M., \& Ferreira, I. C. F. R. (2010). Studies on chemical constituents and bioactivity of Rosa micrantha: An alternative antioxidants source for food, pharmaceutical, or cosmetic applications. Journal of Agricultural and Food Chemistry, 58(10), 6277-6284.

Guimarães, R., Barros, L., Dueñas, M., Carvalho, A. M., Queiroz, M. J. R. P., SantosBuelga, C., \& Ferreira, I. C. F. R. (2013). Characterisation of phenolic compounds in wild fruits from Northeastern Portugal. Food Chemistry, 141, 3721-3730.

Ibañez, F. C., Torre, P., \& Irigoyen, A. (2003). Aditivos alimentarios. Universitas Navarrensis, 1-10.

Jiménez, L., Caleja, C., Prieto, M. A., Barreiro, M. F., Barros, L., \& Ferreira, I. C. F. R. (2018). Optimization and comparison of heat and ultrasound assisted extraction techniques to obtain anthocyanin compounds from Arbutus unedo L. fruits. Food Chemistry, 264, 81-91.

Komatsu, Y., Suematsu, S., Hisanobu, Y., Saigo, H., Matsuda, R., \& Hara, K. (2014). Effects of $\mathrm{pH}$ and temperature on reaction kinetics of catechins in green tea infusion. Bioscience, Biotechnology and Biochemistry, 57(6), 907-910.

Labbé, D., Têtu, B., Trudel, D., \& Bazinet, L. (2008). Catechin stability of EGC- and EGCGenriched tea drinks produced by a two-step extraction procedure. Food Chemistry, 111, 139-143.

Li, N., Taylor, L. S., Ferruzzi, M. G., \& Mauer, L. J. (2012). Kinetic study of catechin stability: Effects of $\mathrm{pH}$, concentration, and temperature. Journal of Agricultural and Food Chemistry, 60, 12531-12539.

Li, N., Taylor, L. S., \& Mauer, L. J. (2011). Degradation kinetics of catechins in green tea powder: Effects of temperature and relative humidity. Journal of Agricultural and Food Chemistry, 59(11), 6082-6090.

Mak, Y. W., Chuah, L. O., Ahmad, R., \& Bhat, R. (2013). Antioxidant and antibacterial activities of hibiscus (Hibiscus rosa-sinensis L.) and Cassia (Senna bicapsularis L.) flower extracts. Journal of King Saud University - Science, 25(4), 275-282.

Martins, N., Roriz, C. L., Morales, P., Barros, L., \& Ferreira, I. C. F. R. (2016). Food colorants: Challenges, opportunities and current desires of agro-industries to ensure consumer expectations and regulatory practices. Trends in Food Science and Technology, 52, 1-15.

Miguel, M. G., Faleiro, M. L., Guerreiro, A. C., \& Antunes, M. D. (2014). Arbutus unedo L.: Chemical and biological properties. Molecules, 19(10), 1579-15823.

Pinela, J., Prieto, M. A., Carvalho, A. M., Barreiro, M. F., Oliveira, M. B. P., Barros, L., \& Ferreira, I. C. F. R. (2016). Microwave-assisted extraction of phenolic acids and flavonoids and production of antioxidant ingredients from tomato: A nutraceutical-oriented optimization study. Separation and Purification Technology, 164, 114-124.

Prieto, M. A., Vázquez, J. A., \& Murado, M. A. (2012a). A simple pseudo-mechanistic model for the response characterization and quantification of the copper-induced oxidative LDL method. Free Radical Biology and Medicine, 53, S245.

Prieto, M. A., Vázquez, J. A., \& Murado, M. A. (2012b). Comparison of several mathematical models for describing the joint effect of temperature and ph on glucanex activity. Biotechnology Progress, 28(2), 372-381.

Prior, R. L., \& Wu, X. (2006). Anthocyanins: Structural characteristics that result in unique metabolic patterns and biological activities. Free Radical Research, 40(10), 1014-1028.

Ruiz-Rodríguez, B.-M., Morales, P., Fernández-Ruiz, V., Sánchez-Mata, M.-C., Cámara, M., Díez-Marqués, C., ... Tardío, J. (2011). Valorization of wild strawberry-tree fruits (Arbutus unedo L.) through nutritional assessment and natural production data. Food Research International, 44(5), 1244-1253.

Sang, J. J., Sang, J. J., Ma, Q., Hou, X. Fang, \& Li, C. Qin (2017). Extraction optimization and identification of anthocyanins from Nitraria tangutorun Bobr. seed meal and establishment of a green analytical method of anthocyanins. Food Chemistry, 218, 386-395.

Sarmento, A., Barros, L., Fernandes, Â., Carvalho, A. M., \& Ferreira, I. C. (2015). Valorization of traditional foods: Nutritional and bioactive properties of Cicer arietinum L. and Lathyrus sativus L. pulses. Journal of the Science of Food and Agriculture, 95(1), 179-185.

Soković, M., Glamočlija, J., Marin, P. D., Brkić, D., \& van Griensven, L. J. L. D. (2010). Antibacterial effects of the essential oils of commonly consumed medicinal herbs using an in vitro model. Molecules, 15(11), 7532-7546.

Soković, M., \& van Griensven, L. J. L. D. (2006). Antimicrobial activity of essential oils 
and their components against the three major pathogens of the cultivated button mushroom, Agaricus bisporus. European Journal of Plant Pathology, 116(3), 211-224.

Su, Y. L., Leung, L. K., Huang, Y., \& Chen, Z. Y. (2003). Stability of tea theaflavins and catechins. Food Chemistry, 83, 189-195.

Takwa, S., Caleja, C., Barreira, J. C. M., Soković, M., Achour, L., Barros, L., \& Ferreira, I. C. F. R. (2018). Arbutus unedo L. and Ocimum basilicum L. as sources of natural preservatives for food industry: A case study using loaf bread. LWT - Food Science and Technology, 88(Supplement C), 47-55.

Timberlake, C. F., \& Henry, B. S. (1988). Anthocyanins as natural food colorants. Progress in Clinical and Biological Research, 280, 107-121.

Ziani, B. E. C., Calhelha, R. C., Barreira, J. C. M., Barros, L., Hazzit, M., \& Ferreira, I. C. F. R. (2015). Bioactive properties of medicinal plants from the Algerian flora: Selecting the species with the highest potential in view of application purposes. Industrial Crops and Products, 77, 582-589.

Zhu, O. Y., Holt, R. R., Lazarus, S. A., Ensunsa, J. L., Hammerstone, J. F., Schmitz, H. H., \& Keen, C. L. (2002). Stability of the flavan-3-ols epicatechin and catechin and related dimeric procyanidins derived from cocoa. Journal of Agricultural and Food Chemistry, 50(6), 1700-1705.

Zhu, Q. Y., Zhang, A., Tsang, D., Huang, Y., \& Chen, Z. (1997). Stability of Green Tea Catechins, 4624-4628.

Ziyyat, A., Mekhfi, H., Bnouham, M., Tahri, A., Legssyer, A., Hoerter, J., \& Fischmeister, R. (2002). Arbutus unedo induces endothelium-dependent relaxation of the isolated rat aorta. Phytotherapy Research, 16, 572-575. 